\title{
IMPACT OF FLIGHT ALTITUDE ON UNMANNED AERIAL PHOTOGRAMMETRIC SURVEY OF THE SNOW HEIGHT ON MOUNT LEBANON
}

\author{
C. Abou Chakra ${ }^{1,2, *}$, J. Somma ${ }^{1}$, S. Gascoin ${ }^{3, *}$, P. Fanise ${ }^{3}$, L. Drapeau ${ }^{3}$ \\ ${ }^{1}$ Laboratoire de Télédétection, Centre de Recherche en Environnement-Espace Méditerranée Orientale, \\ Université Saint-Joseph, Beirut, Lebanon - charbel.abouchakra@gmail.com \\ ${ }^{2}$ Arab Union of Surveyors, Beirut, Lebanon \\ ${ }^{3}$ CESBIO, Université de Toulouse, CNES/CNRS/INRA/IRD/UPS, Toulouse, France
}

KEY WORDS: UAV, Snow height, Agisoft, Structure from Motion, Photogrammetry, Karst

\begin{abstract}
:
In Lebanon, the seasonal snowpack is poorly monitored despite its importance for water resource supply. The snow accumulates on Mount Lebanon in karstic depressions named "sinkholes." It is important to monitor the evolution of the snow height inside those "sinkholes", because of their key role as "containers" for seasonal snow. UAV photogrammetry is a major technological breakthrough which allows an accurate monitoring of the snow height. Because the impact of flight parameters on snow height retrievals is not well documented yet, this research aims to evaluate the impact of UAV flight altitude on the resolution and accuracy of the resulting orthomosaic and DSM. The flight missions were done using the Phantom DJI which generated five DSMs. These are validated using total station measurements.

The results indicate that the snow DSMs can be retrieved by adopting a resolution of 8 to $84 \mathrm{~cm}$, a point density between 1.43 and 153 points $/ \mathrm{sqm}$ and a RMSE of 13 to $41 \mathrm{~cm}$. The testing was done using an elevation varying between 50 and $500 \mathrm{~m}$. The results will be compared to total station observations. These results allow the user to choose the suitable flight altitude for required resolution and points density. We suggest that a flight altitude of $100 \mathrm{~m}$ is sufficient for the survey of the snow cover elevation.
\end{abstract}

\section{INTRODUCTION}

In many Mediterranean regions, meltwater runoff from the seasonal snow cover provides essential water resources (Fayad et al., 2017). This is the case in Lebanon where most of the precipitations fall as snow in winter in high elevation regions (Shaban, 2011; Shaban et al., 2004; Telesca et al., 2014). The snow covers around 25\% of the total Lebanese territory in winter (Shaban et al., 2004; Telesca et al., 2014; Mhawej et al., 2014). It is estimated that at least $30 \%$ of rivers and spring discharges originate from the snow melt (Telesca et al., 2014; Mhawej et al., 2014; Fayad et al., 2017). Although Lebanon is one of the richest countries in terms of precipitations in the Middle East, water restrictions are common during summer. This is partly due to the mismanagement of available water resources, but also to climate change which has caused severe droughts in recent years. A continuous and accurate monitoring of the snowpack is of utmost importance to improve the management of the lebanese water resource and to understand the sensitivity of the snow resource to climate (Somma et al., 2014; Fayad, 2017). Numerous karstic depressions, "sinkholes", punctuate Mount Lebanon high plateaus and play the role of "containers" for the seasonal snow (Somma et al., 2014). They slow down the melting process as they protect the snowpack from the wind and sun radiation. This process delays the low flow period (Shaban, 2011; Somma et al., 2014). Therefore, it is useful to focus the observation of the snow cover evolution inside those depressions in particular to anticipate the beginning of low flow season.

About 50 years ago, pioneering studies were devoted to map snow height by photogrammetry using scanned aerial imagery (Smith et al., 1967). Cline (1993) studied the topic in detail
(1993, 1994) with mixed results. Recently, the development of Unmanned Aerial Vehicles (UAVs) equipped with a digital camera for Digital Surface Model (DSM) generation has opened new perspectives for the study of the snow cover. The snow height distribution can be obtained from UAV surveys at submeter resolution with decimetric to centimetric vertical accuracy (Bühler et al., 2016; Harder et al., 2016; Marti et al., 2016, Cimoli et al., 2017; Avanzi et al., 2018; Lendzioch et al. 2019). The snow height is obtained by subtracting a snow-on DSM and a snow-off DSM, computed with a structure-frommotion (SfM) algorithm of overlapping photographs taken by the digital camera onboard the UAV. In addition to the good accuracy of UAV-derived snow height maps, UAV are increasingly used in snow science as well as in other fields of geoscience (Kelleher et al., 2018; Niedzielski 2018) because they can be operated without a licensed pilot onboard and provide a low-cost solution in comparison with manned aircraft surveys. Not only are UAVs safer to use than an aircraft but they can also fly very close (few meters and above) to the ground (Brunier et al., 2016). However, UAVs offer a limited spatial coverage compared to a manned aircraft (Nolan et al., 2015) or even satellite stereoscopic images (Marti et al. 2016; Deschamps-Berger et al. 2020; Shaw et al. 2020).

A key parameter to increase spatial coverage during a UAV survey is the flight altitude. Higher flight altitudes make it possible to cover larger areas over the same time period, but at the cost of a coarser spatial resolution and accuracy in the final DSM (Leitao et al., 2016; Doumit, 2018; Doumit and Pogorelov 2018).

\footnotetext{
$\overline{* \text { Corresponding author }}$
} 
To our knowledge, this tradeoff has not been documented in the context of snow-covered areas. Here, we apply UAV photogrammetry and SfM to compute DSMs by testing the speed, altitude flight, and processing on different resolutions (low, medium, high). All tests were validated by total station instrument measurements.

\section{STUDY AREA}

This study is focusing on an area located in Jabal El Dib in the upper mountains of Ouyoun al-Siman at 2,300 meters above sea level (Figure 1). The studied site has an area of around 13500 sqm with an altitude between $2313 \mathrm{~m}$ to $2330 \mathrm{~m}$ above sea level. It represents a pilot site for snow studies in Lebanon (Mzaar weather station, Fayad et al. 2017) as the snow can remain until the end of July or August.

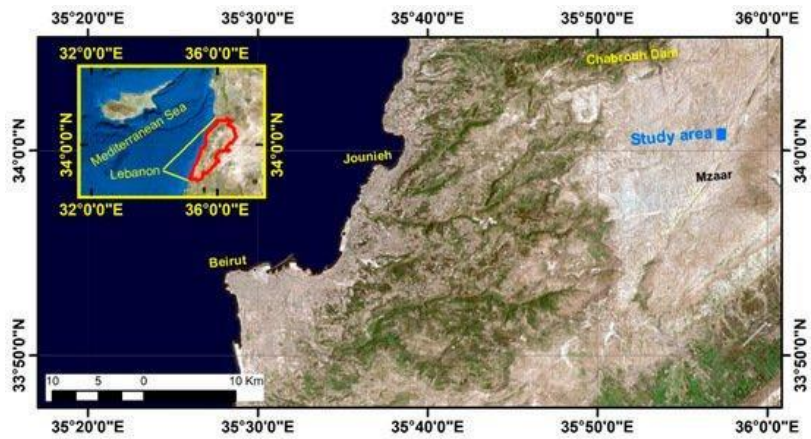

Figure 1: Localization map (Abou Chakra et al., 2019)

\section{MATERIALS AND METHODS}

\subsection{Field measurements}

UAV photogrammetric surveys were done using a "Phantom 3 Advanced DJI" (Figure 2). This UAV is equipped with a builtin camera of 12 megapixels, and with an autonomous 17minutes of flying for each fully charged battery. The Positions of the cameras in the global coordinate system were measured during the flight using a standard GNSS receiver mounted on the UAV, without using the real-time kinematic (RTK) solution. In this context the camera position and orientation were estimated by using ground control points (GCPs) during the photogrammetric restitution process (Aguera-Vega et al., 2016).

Total stations (Figure 3) have been until now one of the main tools used for millimetric precision and accuracy in surveys field, including topography, hydrography, construction, geography, hydrology (Lavine et al., 2003). In this study, the "Leica TS06" total station was used to (i) measure the nine GCPs (Figure 4) (ii) measure 187 points on the snow cover DSM (Figure 4) as a reference dataset to validate the DSM obtained by UAV photogrammetry.

The points dataset measured with the total station is considered as ground truth with maximum errors of $1 \mathrm{~cm}$ and one point, each 5 to $10 \mathrm{~m}$ (Figure 4). Although, this instrument does not provide high density in comparison to a Terrestrial Laser Scanner (TLS) and Structure from Motion (SfM) that could reach much more than 200 points/sqm; we can be sure of the accuracy of each measured point individually. The accuracy of the UAV DSMs was estimated using the residuals of the elevation between the total station measurements and the DSM value at the point location. Standard deviation, means and maximum errors are used to evaluate the accuracy of each extracted DSM from the different flight altitudes.

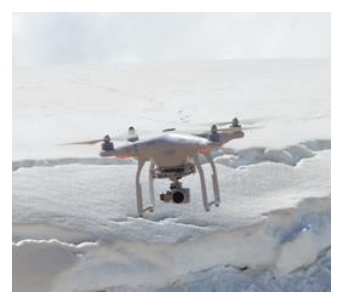

Figure 2: Phantom III Advance picture during flight mission at Jabal El Dib on March 28th 2017.
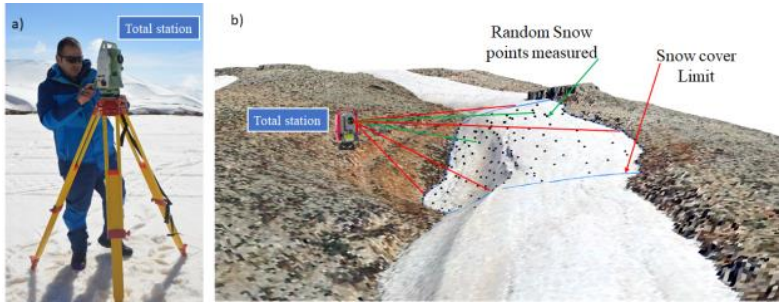

Figure 3: a) Total station; b) random points and survey.

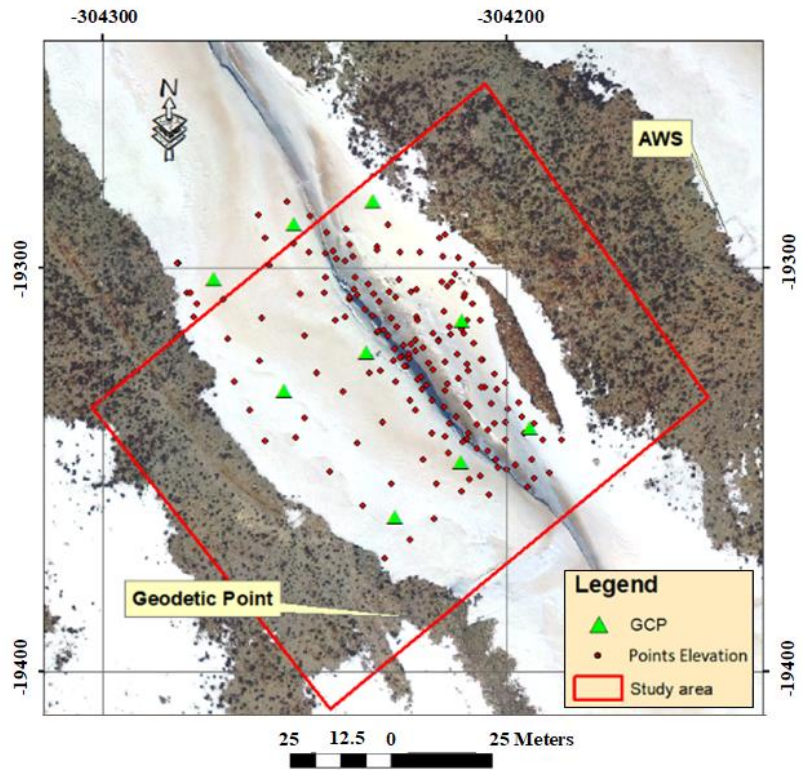

Figure 4: Distribution of the measured points elevation with total station (coordinate system: Deir ez Zor Levant Stereographic).

In order to respect aerial photogrammetric rules, suitable flight planning should be designed and carried out (Ruiz et al., 2013; Gandor et al., 2015). Aerial photos without enough overlap become useless for generating DSMs and orthophotos. Accordingly, mission planning is considered as a critical phase for successful DSM generation (Cimoli et al., 2017). Five missions were prepared, each one having a different altitude flight (Figure A1). The flight mission parameters were set using a mobile autopilot Android application named Litchi. As for the interval between two consecutive images, it was adjusted to two seconds which was the minimum interval choice. The five UAV missions were conducted with the same overlap (70-80\% along the flight line and $60-70 \%$ as side overlap (Figure 5) following the guidelines proposed by Agisoft (2016). The Litchi 
application allows the placing of waypoints to have parallel lines, which will represent the autopilot path of the drone while carrying out the mission.

Many times this experiment was unsuccessful due to technical and logistical problems such as low battery, wind speed or lack of authorization. However, on March 28th 2017 we achieved the five flights as planned $F A=50 \mathrm{~m}, F A=100 \mathrm{~m}, F A=200 \mathrm{~m}$, $\mathrm{FA}=350 \mathrm{~m}$ and $\mathrm{FA}=500 \mathrm{~m}$. .

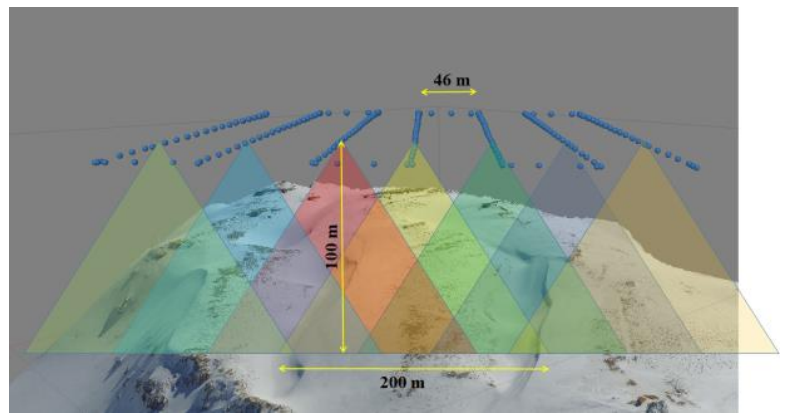

Figure 5: Example of obtained picture location and their sidelap at $\mathrm{FA}=100 \mathrm{~m}$.

\subsection{Data processing}

The processing was performed on a custom-built laptop running an Intel(R) Core (TM) i7-6700 HQ CPU @2.60GHz 2.59 GHz with 4 cores and $32 \mathrm{~GB}$ of memory DDR4. The computer GPU is an Intel® HD Graphics 530 DDR4.

All the processing of aerial images was done using Agisoft Photoscan. Agisoft allows to choose a dense cloud quality and the level of alignment accuracy (Morgan et al., 2016). For the latter we tried to adjust and change the alignment accuracy setting from "lowest" to "medium" and then "highest". We then alternated the dense cloud quality setting between "lowest","medium" and "ultra-high".

As shown by (Abou Chakra 2018) regarding the quality of processing under Agisoft Photoscan, the "medium resolution" processing has been chosen. We also tested the impact of flight speed by performing two flights; one with the maximum speed of $54 \mathrm{~km} / \mathrm{h}$ and another with a speed of about $13 \mathrm{~km} / \mathrm{h}$. The results suggest that the speed change did not modify the DSM (Figure 6). Thus, flight missions will be possible using maximum speed, which will enable covering a larger area without having to worry about speed constraints. It will also help to be more efficient with the batteries of the UAVs, as flight times will be shorter.

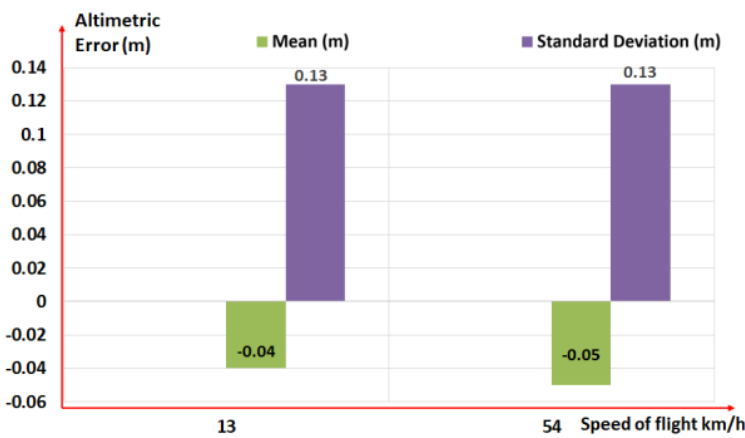

Figure 6: Impact of different speed flight (13 and $54 \mathrm{~km} / \mathrm{h}$ ) on DSM accuracy.

\section{RESULTS AND DISCUSSION}

In our experiment, five DSMs for the same study area with different spatial resolution were obtained from the UAV at different flight altitudes (50m, 100, 200, 350m, 500m). Inside the same area, 187 points were measured by (using a) total station. A comparative procedure has been established by subtracting the elevation value obtained by Total station from the elevation value obtained on the five DSM that were extracted from the five different flight altitudes missions. The assessment of the DSMs will be shown first, according to the resolution, and second, according to the accuracy.

Firstly, the results shows a notable decrease of point cloud density with increasing flight altitudes (Figure 7 and Table 1). The points cloud density varies from 1.43 points $/ \mathrm{m} 2$ at $\mathrm{FA}=500 \mathrm{~m}$ (which is sufficient to flat areas) to 156 points $/ \mathrm{m} 2$ at $\mathrm{FA}=50 \mathrm{~m}$, ; which is very valuable for high slopes. The dense clouds are fundamental to obtain DSMs and Orthomosaics. In this context, the results show that DSM pixel sizes are equal to $8 \mathrm{~cm}, 16 \mathrm{~cm}, 32 \mathrm{~cm}, 58 \mathrm{~cm}, 84 \mathrm{~cm}$ and Ground Sample Distance (GSD) of the orthomosaic are equal to $2 \mathrm{~cm}, 4 \mathrm{~cm}, 8.2 \mathrm{~cm}, 15 \mathrm{~m}$, $21 \mathrm{~cm}$ for flight altitudes of $50 \mathrm{~m}, 100 \mathrm{~m}, 200 \mathrm{~m}, 350 \mathrm{~m}$ and $500 \mathrm{~m}$ respectively (Table 1 ). The variation of GSD directly affects the texture sharpness as shown in (Figure A2), since we lose the clarity of the image. In fact, at FA $=50 \mathrm{~m}$ the GCPs are very clear, at $F A=100 \mathrm{~m}$ and $\mathrm{FA}=200 \mathrm{~m}$ the $\mathrm{GCPs}$ remains quite clear and at $\mathrm{FA}=350 \mathrm{~m}$ and $\mathrm{FA}=500 \mathrm{~m}$ the GCPs are almost impossible to be distinguished. In addition, variation in DSM resolution, affect the representation of terrain roughness (Figure A3).

Secondly, linear regression is observed from the correlation scatterplots of all the elevation values that have been used. The correlation was established between UAV DSM at diverse altitude-flights, using the total station measurements (Figure 8). Although the coefficient of determination $\mathrm{R}^{2}$ is equal to $99 \%$ for all altitudes flights; means, standard deviation, RMSE, minimum and maximum have notable different values. The Table 1 and Figure A4 for the flight altitudes $\mathrm{FA}=50 \mathrm{~m}, \mathrm{FA}=$ $100 \mathrm{~m}, F A=200 \mathrm{~m}, F A=350 \mathrm{~m}$ and $\mathrm{FA}=500 \mathrm{~m}$, show respectively: i) means equal to $-0.02 \mathrm{~m},-0.04 \mathrm{~m},-0.04 \mathrm{~m},-0.04 \mathrm{~m}$, $0.03 \mathrm{~m}$ and $0.13 \mathrm{~m}$; ii) standard deviation equal to $0.13 \mathrm{~m}, 0.14 \mathrm{~m}$, $0.20 \mathrm{~m}, 0.26 \mathrm{~m}$ and $0.39 \mathrm{~m}$; iii) RMSE equal to $0.13 \mathrm{~m}, 0.14 \mathrm{~m}$, $0.20 \mathrm{~m}, 0.26 \mathrm{~m}, 0.39 \mathrm{~m}$; iv) minimum equal to $-0.27 \mathrm{~m},-0.45 \mathrm{~m}$, $0.98 \mathrm{~m},-1.09 \mathrm{~m}$ and $-1.83 \mathrm{~m}$; v) maximum equal to $0.94 \mathrm{~m}$, $0.67 \mathrm{~m}, 0.73 \mathrm{~m}, 0.66 \mathrm{~m}, 0.63 \mathrm{~m}$.

By analyzing the results more deeply to understand the impact of the flight altitude on the different error positions, the RMSE above $|30 \mathrm{~cm}|$ has been selected for each flight altitude (Figure A5). Remarkable errors were found on a snow cornice (Figure 7 and Figure 9) and on the steep slope under it; which highlights the importance of the density of the point cloud. Going deeper, a sample section is created along the study area (Figure 9). This figure shows a sample section that is selected in the middle of the study area. (Figure 10) focuses on the representation of cornice graphics, blending the results of the total station and the UAV at diverse flight altitudes.

High flight altitudes see a decrease of the DSM resolution, which affects the accuracy. As shown in (Figure 10 and Figure A5) the majority of errors above $30 \mathrm{~cm} /$ are located on the steep changing slope which is the cornice location. In this location, the pixel size of the DSM is very critical to represent the real 
shape of the snow. The low density point cloud causes the rasterization, and the profile will be shown as a staircase $(\mathrm{FA}=500 \mathrm{~m})$ instead of a curved shape $(\mathrm{FA}=50 \mathrm{~m})$. Therefore we can understand the high minimum and maximum errors shown in (Table 1 and Figure A6) according the flight altitude changes.

\begin{tabular}{|c|c|c|c|c|c|c|c|c|c|c|}
\hline $\begin{array}{c}\text { UAV } \\
\text { Flight } \\
\text { Altitude } \\
\text { (m) }\end{array}$ & $\begin{array}{l}\text { Points } \\
\text { Count }\end{array}$ & $\begin{array}{l}\text { Captured } \\
\text { images }\end{array}$ & $\begin{array}{c}\text { Points } \\
\text { density } \\
\text { (points/sqm) }\end{array}$ & $\begin{array}{l}\text { Min } \\
(\mathrm{m})\end{array}$ & $\begin{array}{c}\text { Max } \\
\text { (m) }\end{array}$ & $\begin{array}{c}\text { Mean } \\
(\mathrm{m})\end{array}$ & $\begin{array}{c}\text { Standard } \\
\text { Deviatio } \\
\text { n (m) }\end{array}$ & $\begin{array}{c}\text { RMSE } \\
\text { (m) }\end{array}$ & $\begin{array}{c}\text { GSD } \\
\text { (m) }\end{array}$ & $\begin{array}{c}\text { DEM } \\
\text { Resolution } \\
\text { (m) }\end{array}$ \\
\hline 50 & \multirow{5}{*}{187} & 60 & 156 & -0.27 & 0.94 & -0.02 & 0.13 & 0.13 & 0.02 & 0.08 \\
\hline 100 & & 20 & 38.4 & -0.45 & 0.67 & -0.04 & 0.14 & 0.14 & 0.04 & 0.16 \\
\hline 200 & & 12 & 9.2 & -0.98 & 0.73 & -0.04 & 0.20 & 0.20 & 0.82 & 0.32 \\
\hline 350 & & 10 & 2.96 & -1.09 & 0.66 & 0.03 & 0.26 & 0.26 & 0.15 & 0.58 \\
\hline 500 & & 8 & 1.43 & -1.82 & 0.63 & 0.13 & 0.39 & 0.41 & 0.21 & 0.84 \\
\hline
\end{tabular}

Table 1: Statistical results according to each flight altitude

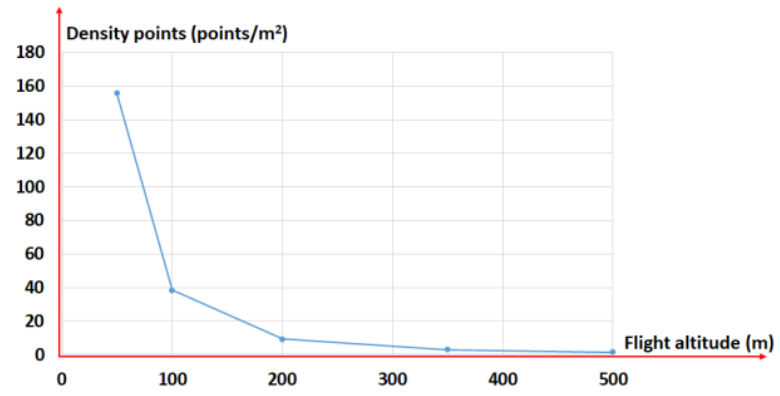

Figure 7: point cloud density according to flight altitude.
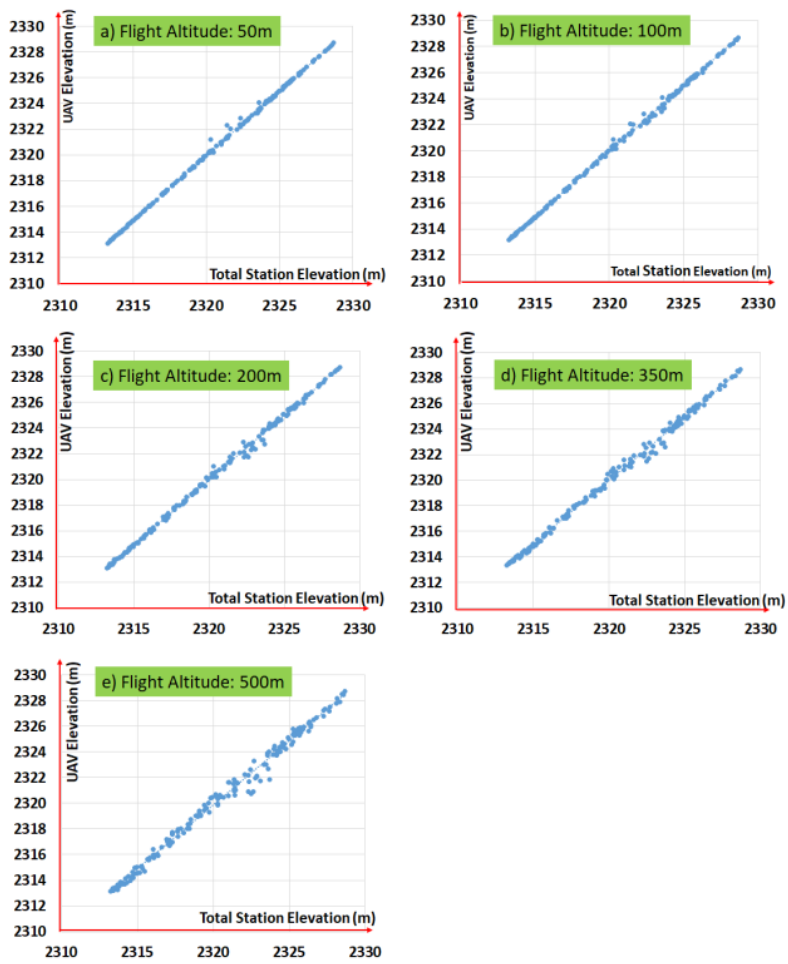

Figure 8: Scatter plot of correlation between DSM total station and UAV DSM at diverse altitudes: a) $50 \mathrm{~m}$, b) $100 \mathrm{~m}$, c) $200 \mathrm{~m}$ d) $350 \mathrm{~m}$, e) $500 \mathrm{~m}$

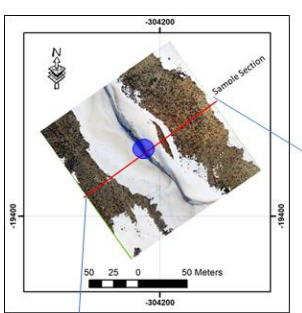

a) Orthophoto

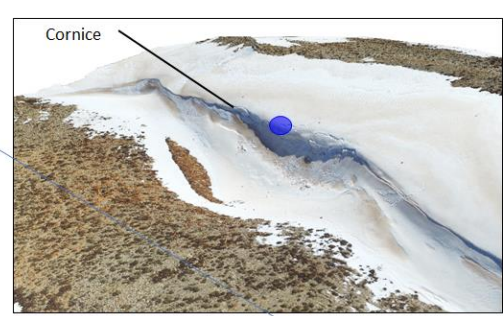

b) Isometric view

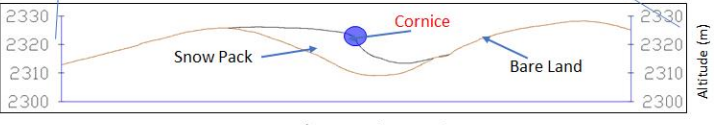

c) Sample section

Figure 9: a) Aerial orthophoto and sample section location on the study area; b) isometric view showing the cornice location and shape; c) sample profile

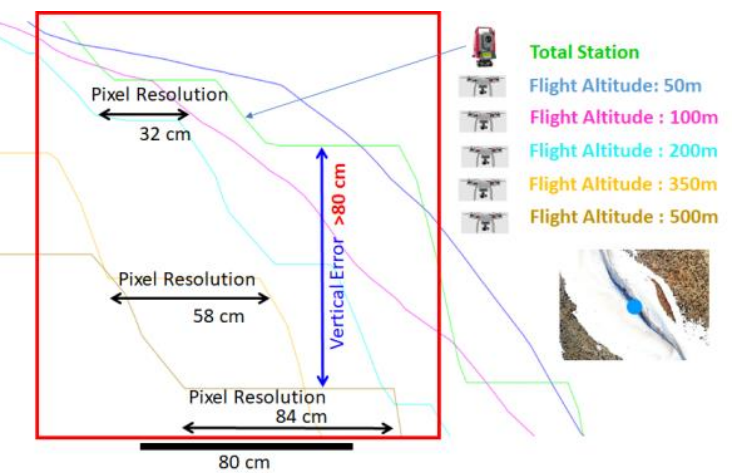

Figure 10: Comparison of altitude along the sample section extracted from Total Station and UAV at different altitude flight. The red rectangle represents the blue circle of the cornice location in Figure 9

\section{CONCLUSION}

Five different UAV surveys of the snow cover elevation were done with varying altitudes of $50 \mathrm{~m}, 100 \mathrm{~m}, 200 \mathrm{~m}, 350 \mathrm{~m}$, and $500 \mathrm{~m}$. The optimal DSM resolution increased from $8 \mathrm{~cm}$ at 50 $\mathrm{m}$ high to $84 \mathrm{~cm}$ at $500 \mathrm{~m}$ high; with the point density decreasing from 156 points/sqm to 1.43 points/sqm. As expected, the flight altitude of $50 \mathrm{~m}$ gave the sharpest terrain texture, offered the best GCPs visibility and the best representation of relief in particular for the steepest slopes. However, higher altitude flights provided a larger field of view. Based on this study we suggest that a flight altitude of $100 \mathrm{~m}$ is the best trade-off between accuracy and coverage, especially because it is compatible with the European regulation, which permits UAVs weighing less than $25 \mathrm{~kg}$. With a RMSE of 14 $\mathrm{cm}$, this configuration can be used to characterize the snow height distribution with sufficient accuracy over complex terrains in Mount Lebanon.

\section{ACKNOWLEDGEMENTS}

This project is a collaboration between Université Saint Joseph, Institut de la Recherche pour le Développement and CESBIO in the framework of the Observatoire Franco-Libanais pour l'Environnement (O-LIFE). We thank the Research Council at USJ and UNICEF for the financial support. We also thank the Direction of Orientation, the Intelligence and Aerial forces of Lebanese army because they gave us authorisations to use the aircraft. 


\section{REFERENCES}

Abou Chakra, C., Gascoin, S., Somma, J., Fanise, P., Drapeau, L., 2019. Monitoring the Snowpack Volume in a Sinkhole on Mount Lebanon using Time Lapse Photogrammetry. Sensor. https://doi.org/10.3390/s19183890.

Abou Chakra, C., 2018. Innovative approaches for high precision monitoring of snow cover, Mount Lebanon. PhD thesis, pp 396.

Avanzi, F., Bianchi, A.; Cina, A., De Michele, C., Maschio, P., Pagliari, D., Passoni, D., Pinto, L., Piras, M., Rossi, L. 2018. Centimetric Accuracy in Snow Depth Using Unmanned Aerial System Photogrammetry and a MultiStation. Remote Sens. https://doi.org/10.3390/rs10050765

Agisoft PhotoScan User Manual - Professional Edition, Version 1.2., $2016 \quad$ (http://www.agisoft.com/pdf/photoscanpro_1_2_en.pdf)

Agüera-Vega, F., Carvajal-Ramírez, F., Martínez-Carricondo, P. 2016. Assessment of photogrammetric mapping accuracy based on variation ground control points number using unmanned aerial vehicle. Measurement: Journal of the International Measurement Confederation, 98, 221-227. https://doi.org/10.1016/j.measurement.2016.12.002

Brunier, G., Fleury, J., Anthony, E. J., Gardel, A., Dussouillez, P. 2016. Close-range airborne Structure-from-Motion Photogrammetry for high-resolution beach morphometric surveys: Examples from an embayed rotating beach. Geomorphology, 261, 76-88. https://doi.org/10.1016/j.geomorph.2016.02.025

Bühler, Y., Adams, M. S., Bösch, R., Stoffel, A., 2016 Mapping snow depth in alpine terrain with unmanned aerial systems (UASs): potential and limitations. The Cryosphere, 10, 10751088, https://doi.org/10.5194/tc-10-1075-2016

Cimoli, E., Marcer, M., Vandecrux, B., Bøggild, C.E., Williams, G., Simonsen, S.B. Application of Low-Cost UASs and Digital Photogrammetry for High-Resolution Snow Depth Mapping in the Arctic. Remote Sens, 9, 1144. https://doi.org/10.3390/rs9111144

Cline, D. W., 1993. Measuring Alpine Snow Depths by Digital Photogrammetry - Part 1: Conjugate Point Identification. Proceedings 50th Eastern Snow Conference, Quebec.

Deschamps-Berger, C., Gascoin, S., Berthier, E., Lacroix, P., Polidori L., 2020. La Terre en 4D : apport des séries temporelles de modèles numériques d'élévation par photogrammétrie spatiale pour l'étude de la surface terrestre, Revue Française de Photogrammétrie et de Télédétection, 221.
Doumit, J. A., 2018. Multiscale Landforms Classification Based on UAV Datasets, 3(2), 128-141. https://doi.org/10.22158/se.v3n2p128

Doumit, J. A., Pogorelov, A. V., 2018. Multi-scale Analysis of Digital Surface Models Based on UAV Datasets. Modern Environmental Science and Engineering, 03(07), 460-468. https://doi.org/10.15341/mese(2333-2581)/07.03.2017/004

Fayad, A., Gascoin, S., Faour, G., Fanise, P., Drapeau, L., Somma, J., Fadel, A., Al Bitar, A., Escadafal, R., 2017 Snow observations in Mount-Lebanon (2011-2016), Earth Syst. Sci. Data, 9, 573-587, doi:10.5194/essd-9-573-2017.

Gandor, F., Rehak, M., \& Skaloud, J., 2015. Photogrammetric mission planner for RPAS. The International Archives of the Photogrammetry, Remote Sensing and Spatial Information Sciences, Volume $\quad X L-1 / W 4, \quad 2015$. https://doi.org/10.5194/isprsarchives-XL-1-W4-61-2015

Harder, P.; Schirmer, M.; Pomeroy, J.; Helgason, W. Accuracy of snow depth estimation in mountain and prairie environments by an unmanned aerial vehicle. Cryosphere 2016, 10, 25592571.

Kelleher, C., Scholz, C.A., Gondon, L., Reardon, M., 2018. Drones in geoscience research: The sky is the only limit, Eos, 99, https://doi.org/10.1029/2018E0092269

Lavine, A., Gardner, J. N., Reneau, S. L, 2003. Total station geologic mapping: An innovative approach to analyzing surface-faulting hazards. Engineering Geology, 70(1-2), 71-91. https://doi.org/10.1016/S0013-7952(03)00083-8

Leitão, J. P., Moy De Vitry, M., Scheidegger, A., Rieckermann, J., 2016). Assessing the quality of digital elevation models obtained from mini unmanned aerial vehicles for overland flow modelling in urban areas. Hydrology and Earth System Sciences, 20(4), 1637-1653. https://doi.org/10.5194/hess-20$\underline{1637-2016}$

Lendzioch, T, Langhammer, J., Jenicek, M., 2019. Estimating Snow Depth and Leaf Area Index Based on UAV Digital Photogrammetry. Sensors 2019, 19(5), 1027; https://doi.org/10.3390/s19051027

Marti R, Gascoin S, Berthier E, Pinel MD, Houet T, Laffly D., 2016. Mapping snow depth in open alpine terrain from stereo satellite imagery. The Cryosphere. $2016 \mathrm{Jul}$ 4;10(4):1361-80.

Mhawej, M., Faour, G., Fayad, A., Shaban, A., 2014. Towards an enhanced method to map snow cover areas and derive snowwater equivalent in Lebanon. Journal of Hydrology, 513, 274282. https://doi.org/10.1016/j.jhydrol.2014.03.058

Morgan, J. A., Brogan, D. J., Nelson, P. A., 2016. Application of Structure-from-Motion photogrammetry in laboratory flumes. Geomorphology, 276, 125-143. https://doi.org/10.1016/j.geomorph.2016.10.021. 
Niedzielski, T., 2018. Applications of Unmanned Aerial Vehicles in Geosciences: Introduction. Pure and Applied Geophysics, 175(9), 3141-3144.

Nolan, M., Larsen, C., and Sturm, M., 2015. Mapping snow depth from manned aircraft on landscape scales at centimeter resolution using structure-from-motion photogrammetry, The Cryosphere, 9, 1445-1463, https://doi.org/10.5194/tc-9-14452015.

Ruiz, J. J., Diaz-Mas, L., Perez, F., Viguria, A., 2013. Evaluating the Accuracy of Dem Generation Algorithms From Uav Imagery. International Archives of Photogrammetry and Remote Sensing, XL(September), 4-6. https://doi.org/10.5194/isprsarchives-XL-5-529-2014

Shaban, A., Faour, G., Khawlie, M., Abdallah, C. 2004. Remote sensing application to estimate the volume of water in the form of snow on Mount Lebanon / Application de la télédétection à l'estimation du volume d'eau sous forme de neige sur le Mont Liban. Hydrological Sciences Journal, 49(4), 37-41. https://doi.org/10.1623/hysj.49.4.643.54432

Shaban A., Darwish T., 2011. The role of sinkholes in groundwater recharge in the high mountains of Lebanon. Journal of environmental hydrology. Volume 19 paper 9 April 2011; p. 1-12.

Shaw, T., Gascoin, S., Mendoza, C., Pellicciotti, F. McPhee, J., 2020. Snow depth patterns in a high mountain Andean catchment from satellite optical tri-stereoscopic remote sensing, Water Resources Research (in press), doi:10.1029/2019WR024880.

Smith. (1967). Measuring snow depth by aerial photogrammetry. Evaluation and recommendation.

Somma, J., Drapeau, L., Abou Chakra, C. 2014. Caractérisation de la capacité de rétention de neige d'un plateau karstique. Essai méthodologique pour le plateau du Jabal Jraid (Liban). Revue Internationale de Géomatique, 24(1), 87-99. https://doi.org/10.3166/rig.24.87-99

Telesca, L., Shaban, A., Gascoin, S., Darwich, T., Drapeau, L., Hage, M. El, Faour, G., 2014. Characterization of the time dynamics of monthly satellite snow cover data on Mountain Chains in Lebanon. Journal of Hydrology, 519(PD), 32143222. https://doi.org/10.1016/j.jhydrol.2014.10.037.

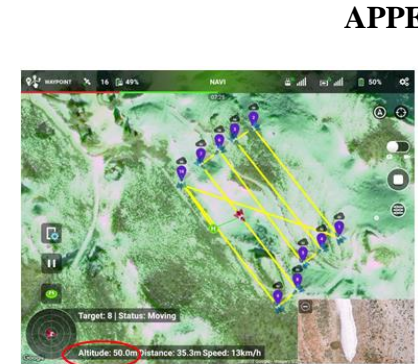

a) Altitude flight: $50 \mathrm{~m}$

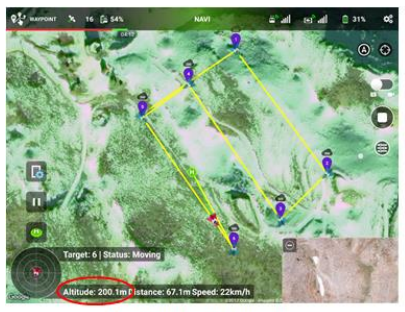

c) Altitude flight: $200 \mathrm{~m}$

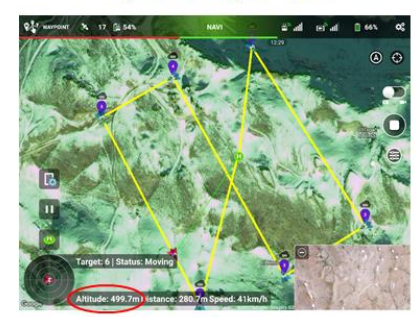

e) Altitude flight: $500 \mathrm{~m}$

Figure A1: The five missions' plans at different altitudes

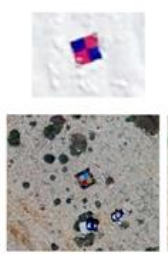

$50 \mathrm{~m}$

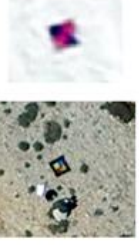

$100 \mathrm{~m}$

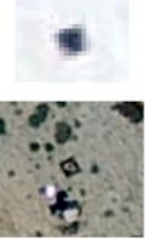

$200 \mathrm{~m}$

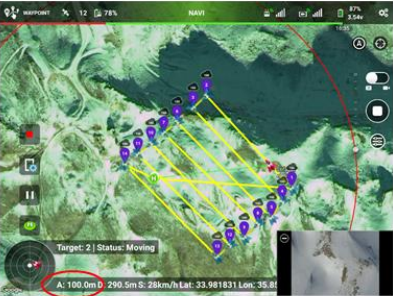

b) Altitude flight: $100 \mathrm{~m}$

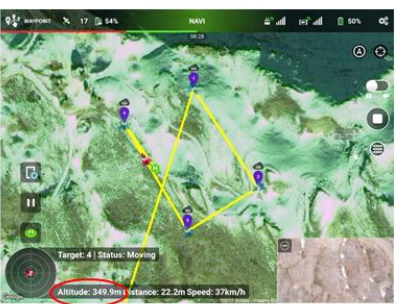

d) Altitude flight: $350 \mathrm{~m}$
Figure A2: a) Temporal GCPs visibility and contrast on snow cover; b) permanent GCPs visibility and contrast on bare land.

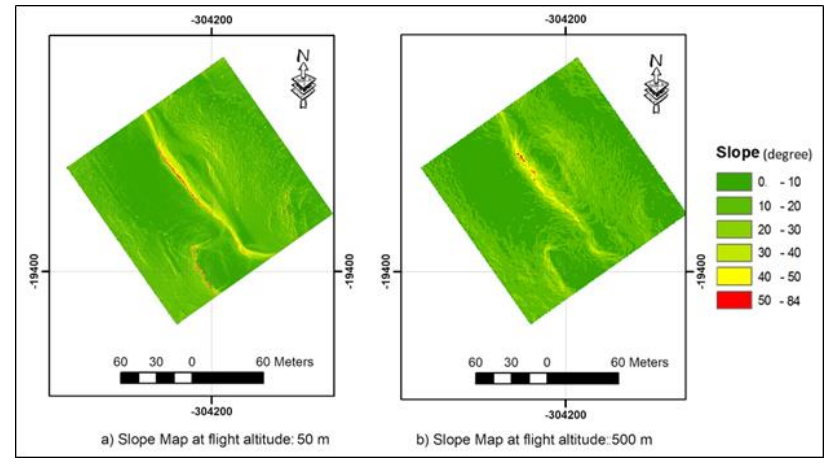

Figure A3: Slope maps for altitude flight 50 and $500 \mathrm{~m}$ 

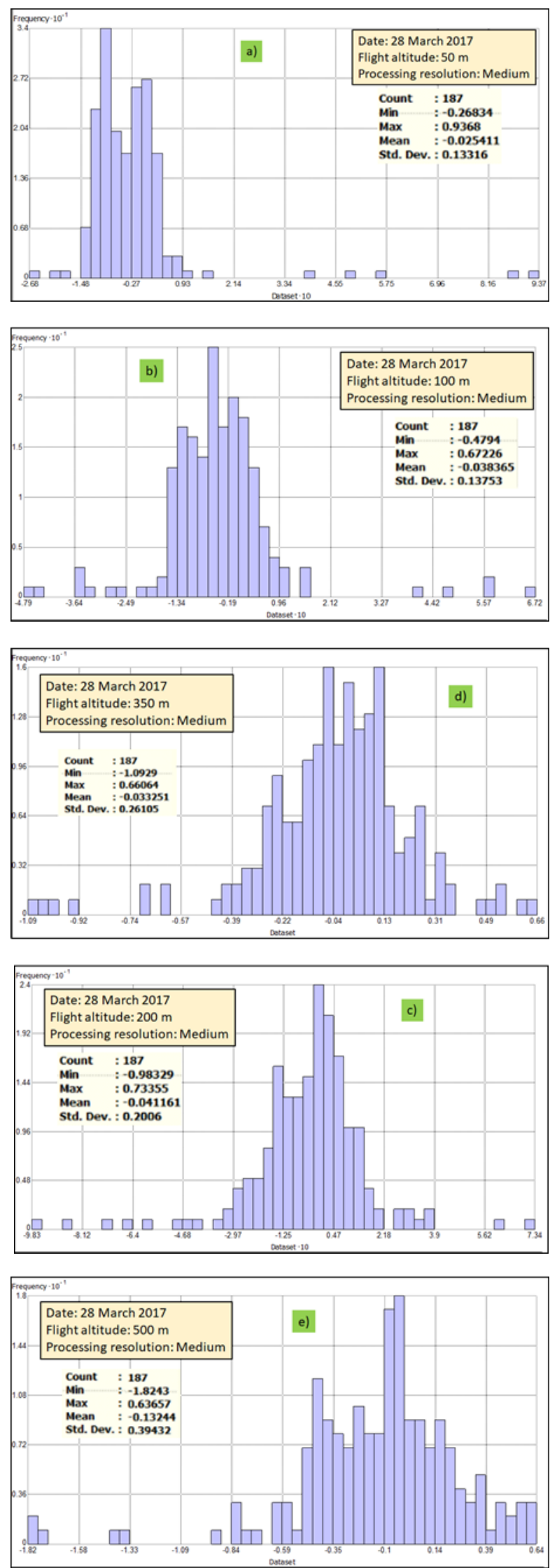

Figure A4: Histogram plot of elevation differences (errors) between measured elevation by total station and the DSM extracted by UAV at diverse altitudes flights
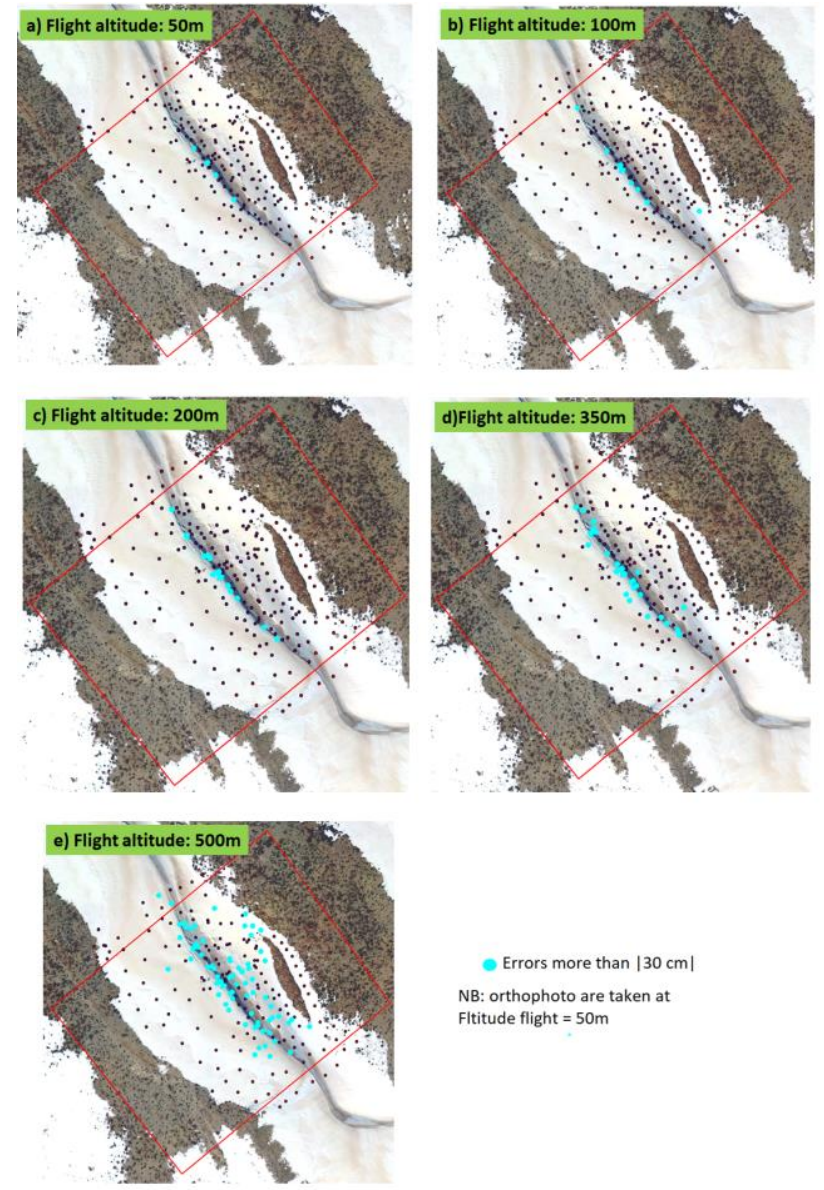

- Errors more than $|30 \mathrm{~cm}|$

NB: orthophoto are taken at

Fltitude flight $=50 \mathrm{~m}$

Figure A5: location of error above $\mid 30 \mathrm{~cm} /$ as per each flight altitude

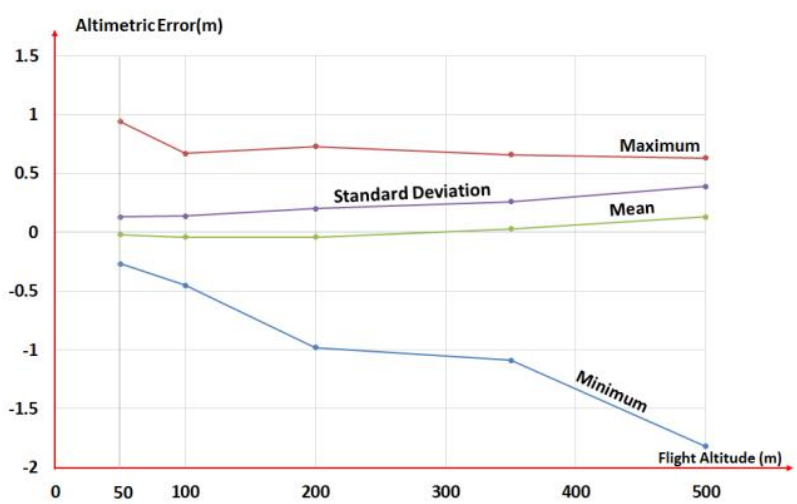

Figure A6: Accuracy of DSM UAV accuracy extracted from multiple flight altitudes comparing to Total Station measurements. 